\title{
Comparative variation in spawning output and juvenile recruitment of some Caribbean reef fishes
}

\author{
D. Ross Robertson, Ursula M. Schober, Jeffrey D. Brawn
}

Smithsonian Tropical Research Institute (Balboa, Panama), Unit 0948, APO AA 34002-0948, USA

\begin{abstract}
It is generally accepted that the intensity of recruitment of pelagic young of temperate marine fishes is determined primarily by events that affect young as larvae, and that pelagic processes substantially increase variation in recruitment over the level expected from variation in spawning output alone. Spawning and recruitment of 6 species of Caribbean damselfishes were monitored monthly at a site in Panama for 1 to 3 yr (1983 to 1987) and 7 to 10 yr (1980 to 1989), respectively. Intermensual variation in recruitment strength exceeded corresponding variation in spawning output by average factors of at least 1.5 to 3.0 (and perhaps as much as 4 to 20) among those species. Serial changes in seasonally-adjusted monthly spawning output and 'resultant' recruitment strength were not correlated in any species. Thus, regardless of whether or not local populations are self-recruiting, pelagic processes evidently do largely control, and substantially enhance, short-term variability in recruitment strength in these fishes. Interannual variation in recruitment was low in all but one species, in which it also exceeded variation in spawning. Thus control of variation in recruitment strength by short-term pelagic processes had little or no net effect on interannual variation in recruitment in most cases. Interspecific differences in recruitment seasonality and in levels of variation in mensual and annual recruitment strength (but not mensual and annual spawning output) indicate that pelagic processes affect recruitment of some of these closely related species to different degrees and in different temporal patterns.
\end{abstract}

\section{INTRODUCTION}

Substantial temporal variation in the intensity of recruitment of juveniles at the end of the pelagic larval phase is characteristic of many temperate (e.g. Cushing 1975, Rothschild 1986) and tropical (Russell et al. 1977, Sale et al. 1984, MacFarland et al. 1985, Victor 1986, Doherty \& Williams 1988, Doherty 1991) marine fishes. Such variation is attributed primarily to processes that affect the survivorship of larvae, and much research on temperate-zone species has been oriented towards identifying pelagic processes that influence recruitment strength on a variety of time scales and quantifying their effects. This includes examinations of relationships between spawning output (often inferred from stock size) and recruitment, and between recruitment strength and change in oceanographic conditions that affect the growth, mortality and dispersal of larvae (e.g. Lasker 1981, Parrish et al. 1981. Bakun et al. 1982, Cushing 1982, Lambert \& Ware 1984, Sherman et al. 1984, Roth- schild 1986, Koslow \& Thompson 1987, Peterman \& Bradford 1987, Checkley et al. 1988, Thresher et al. 1989). Comparatively little similar information is available for tropical species. The relevant data consist of time series up to 10 yr on intra- and interannual variation and spatial variation in recruitment obtained on the Australian Great Barrier Reef. They have been used primarily to examine the spatial coherence of recruitment activity, and to make inferences about oceanographic mechanisms that might produce those spatial patterns (see Doherty \& Williams 1988, Doherty 1991 for reviews). The relationship between variation in the magnitudes of spawning and recruitment apparently has been examined previously in only one tropical reef fish, in which Doherty (1980) found that the ratio of annual levels of spawning and recruitment at a single site varied 13 -fold over $2 \mathrm{yr}$. Thus at present we have a very limited ability to distinguish between effects of variation in spawning output and of pelagic processes on recruitment strength of tropical fishes. 
The relationships between the seasonal cycles of spawning and recruitment of the present study species, a group of 6 closely related Caribbean reef fishes, have been described by Robertson (1990). Here we compare both short-term (intermensual), and longterm (interannual) variation in the intensity of their spawning and recruitment, infer the extent to which intermensual variation in recruitment could be due to short-term pelagic processes and assess whether there are differences in degrees of variation in monthly spawning and recruitment activity in different seasons. Finally we examine the net effect that such processes might have on interannual variation in recruitment strength.

\section{MATERIALS AND METHODS}

Organisms and study site. We monitored spawning and recruitment by 6 species of Caribbean damselfishes (Pomacentridae), Abudefduf saxatilis, Microspathodon chrysurus, Stegastes diencaeus, S. dorsopunicans, S. leucostictus, and $S$. partitus, on fringing reefs at Punta de San Blas, on the Caribbean coast of Panama $\left(9^{\circ} 34^{\prime} \mathrm{N}, 78^{\circ} 57^{\prime} \mathrm{W}\right)$. There are 2 main weather seasons in Panama. The dry season, when northeast trade winds blow fairly constantly, lasts from about mid-December to about mid-April. During the remainder of the year rainfall is higher and winds are lighter and more variable in direction. Sea-surface temperatures range from 26 to $30^{\circ} \mathrm{C}$ (Cubit et al. 1989 , Robertson 1990).

Spawning output. In each species eggs are laid in discrete, densely packed, monolayered clutches in well-defined, prepared nests, which typically are used repeatedly. In each species spawning is lunar periodic and eggs are defended by the male parent until they hatch shortly after dusk, 3.5 to $5.5 \mathrm{~d}$ after spawning (Robertson et al. 1990).

Nests were tagged with flagging tape and censused either at 1 to $2 \mathrm{~d}$ intervals year-round (Abudefduf saxatilis, Stegastes dorsopunicans and S. leucostictus), or at 3 d intervals during the part of each lunar cycle when spawning usually occurred (remaining species). At each census the number of clutches present and the maximum and minimum dimensions of each new clutch (readily distinguished by its color) were recorded. The area of each clutch was estimated by treating it as an ovoid, which is the usual shape. As our measure of per capita output we used the mean number of $\mathrm{cm}^{2}$ of eggs censused per nest (including temporarily unused nests) per month (see also Robertson et al. 1988. Robertson 1990, Robertson et al. 1990).

The reef system in the study area is composed of over 200 discrete patch reefs (Robertson 1987).
Spawning by Microspathodon chrysurus, Stegastes diencaeus and S. partitus was monitored concurrently for 3 yr on 2 patch reefs 1 to $2.5 \mathrm{~km}$ apart. Spawning by $S$. dorsopunicans was monitored on 1 reef for $3 \mathrm{yr}$, and a second reef $(1.5 \mathrm{~km}$ away) during the last year of that period. In each case the 2 reefs chosen provided situations representative of high and low exposure to seasonal change in sea conditions (Robertson 1990). Variation in levels of monthly egg production on the pair of reefs was positively correlated in each species (Pearson $\mathrm{r}=0.52, \mathrm{n}=38, \mathrm{p}<0.01$ for $M$. chrysurus; $\mathrm{r}=$ $0.37, \mathrm{n}=37, \mathrm{p}<0.05$ for $S$. diencaeus; $\mathrm{r}=0.62, \mathrm{n}=12$, $\mathrm{p}<0.05$ for $S$. dorsopunicans; and $\mathrm{r}=0.51, \mathrm{n}=37$, $p<0.01$ for $S$. partitus). We used the average of the 2 monthly spawning-output values from a pair of reefs when estimating levels of variation in spawning. The number of nests monitored, their average levels of egg production and the monitoring periods are shown in Table 1.

Settlement and recruitment. Here settlement refers to the first appearance of the smallest individuals of each species that are observed in benthic habitats. Average sizes of settlers of the study species are ca 10 to $12 \mathrm{~mm}$ standard length and there is little intraspecific variation in those sizes (Robertson 1992). In those species for which data are available (all except Microspathodon chrysurus) settlement is lunar periodic and minimal around full moon (Robertson 1992). The duration of the pelagic stage of the 6 species is about 3 to 5 wk (Robertson et al. 1988, Thresher \& Brothers 1989, Wellington \& Victor 1989).

Recruits of a lunar month are fish that settled during and survived to the end of that lunar cycle (full moon). Monthly recruitment censuses were made during the week before each full moon. During a census each of a set of permanent plots scattered as much as $2.5 \mathrm{~km}$ apart was systematically searched in the same way by the same observer (D.R.R.) and all recruits of the month (recognized by their small size) were recorded. The monitoring schedules and sampling effort are shown in Table 1.

Some assumptions. To assess the effects that pelagic processes have on juvenile settlement one ideally should measure larval production at hatching and abundances of juveniles at settlement. Due to logistic constraints we measured the production of eggs, which develop on the substratum for a few days before the larvae enter the pelagic environment, and the recruitment of young fish about $10 \mathrm{~d}$ after the lunar period of peak settlement.

When estimating larval production we are assuming that egg mortality does not systematically disrupt the relationship between egg production and hatchling production. We evaluated this assumption with Stegastes dorsopunicans. This was the only species 
Table 1. Summary of monitoring data base for spawning and recruitment of some Caribbean damselfishes

\begin{tabular}{|c|c|c|c|c|c|c|}
\hline & $\begin{array}{l}\text { Abuderduf } \\
\text { saxatilis }\end{array}$ & $\begin{array}{l}\text { Microspathodon } \\
\text { chrysurus }\end{array}$ & $\begin{array}{l}\text { Stegastes } \\
\text { diencaeus }\end{array}$ & $\begin{array}{c}\text { Stegastes } \\
\text { dorsopunicans }\end{array}$ & $\begin{array}{l}\text { Stegastes } \\
\text { leucostictus }\end{array}$ & $\begin{array}{c}\text { Stegastes } \\
\text { partitus }\end{array}$ \\
\hline \multicolumn{7}{|l|}{ Spawning output } \\
\hline $\begin{array}{l}\text { No. of patch reef populations } \\
\text { and monitoring period }\end{array}$ & $\begin{array}{l}1 \times 1 y \mathrm{yr} \\
(1987)\end{array}$ & $\begin{array}{l}2 \times 3 \mathrm{yr} \\
(1983-5)\end{array}$ & $\begin{array}{l}2 \times 3 y r \\
(1983-5)\end{array}$ & $\begin{array}{c}1 \times 3 y r+1 \times 1 y r \\
(1985-7)\end{array}$ & $\begin{array}{c}1 \times 3 \text { yr } \\
(1984-6)\end{array}$ & $\begin{array}{l}2 \times 3 y r \\
(1983-5)\end{array}$ \\
\hline $\begin{array}{l}\text { No. of nests monitored } \\
\text { per population }\end{array}$ & 35 & $20-25$ & $20-30$ & $27-40$ & $20-25$ & $20-25$ \\
\hline \multicolumn{7}{|l|}{ Average output nest ${ }^{-1} \mathrm{mo}^{-1}$ d } \\
\hline No. of clutches & 2.0 & 3.1 & 2.1 & 2.0 & 6.6 & 5.6 \\
\hline Total clutch area $\left(\mathrm{cm}^{2}\right)$ & 422 & 238 & 85 & 79 & 105 & 107 \\
\hline \multicolumn{7}{|l|}{ Recruitment } \\
\hline No. sites monitored & 8 & 8 & 6 & - & $-11^{\mathrm{b}}$ & \\
\hline Total area of sites $\left(\mathrm{m}^{2}\right)$ & -14000 & $\sim 1500$ & $>3000$ & 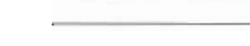 & $\sim \sim 2600^{\mathrm{b}}-$ & \\
\hline Average no. recruits $\mathrm{yr}^{-1}$ & 762 & 106 & 75 & 412 & 94 & 398 \\
\hline No. years monitored (until 1989) & 7 & 7 & 10 & 7 & 7 & 7 \\
\hline
\end{tabular}

for which nests were censused daily over an extended period ( 3 yr). This allowed more precise estimation of egg losses prior to hatching. Hatching occurs on the evening of the fourth day after spawning (Robertson et al. 1990) and we estimated egg mortality using clutches that remained in the nest for $<4 \mathrm{~d}$. The level of egg mortality was not significantly correlated with the level of production of new eggs each month (Pearson $r=-0.29, p>0.05, n=37$ ), and the levels of variation in monthly production of new and last-day eggs did not differ statistically (Levene's Test: $t=1.18, \mathrm{n}=37$, $p>0.20$; see below for details of this test). Thus our assumption that variation in egg production can be used to estimate variation in larval production appears valid.

Does variation in the intensity of recruitment mirror variation in the intensity of settlement? Since early mortality of newly settled reef fishes often is high (Doherty \& Sale 1986, Victor 1986, Sale \& Ferrel 1988, Booth 1991) and can be density dependent (Forrester 1990, but see Victor 1986), it potentially could either increase or decrease variation in the intensity of recruitment relative to that in settlement. Milicich et al. (1992) examined relationships between variation in early recruitment (within $1 \mathrm{wk}$ after settlement) and the influx of late-stage larvae (collected at light-traps) of several damselfishes on the Great Barrier Reef. They concluded that recruitment variation mirrored variation in the settler supply on a spatial scale similar to that used in the present study, and that early postsettlement mortality did not disrupt the settlement/ recruitment relationship. This appears to be the case with our study species. Settlement of 4 of them (no data for the others) was monitored for 4 yr by making daily removals of newly settled fishes from small isolated patch reefs (Robertson 1992). Recruitment was monitored during the same period on nearby reefs. Intermensual variation in the intensity of recruitment and settlement were positively correlated in each of those 4 species. In each case the data fitted a linear relationship better than curvilinear relationships that would have indicated either positive or negative density dependency in recruitment, and enhancement or dampening of settlement variation. In addition, levels of intermensual variation in settlement strength and recruitment strength did not differ in three of those species. While recruitment did vary less than settlement in Abudefduf saxatilis, that difference probably was due simply to the large (200-fold) difference in the spatial scales on which settlement and recruitment were measured in a species whose settlers and recruits are highly aggregated (Robertson 1992). Consequently we treat the level of intermensual variation in recruitment strength as being equivalent to that in settlement strength.

Data analyses. Intermensual variation in spawning and recruitment: We provide data on the range of variation (the maximum/minimum ratio) in recruitment and spawning because such ranges are commonly used to describe variation in recruitment of fishes (e.g. Hennemuth et al. 1980, Rothschild 1986, Doherty \& Williams 1988). However they cannot be compared statistically.

To statistically compare relative levels of variation in spawning and recruitment we used Levene's Test (Schultz 1985). In this test each of the set of sample variates is transformed relative to the sample median [i.e. $Y=\{[X-M(X)] / M(X)\} \times 100 \%$ ] and a t-test is used to compare the means of 2 sets of transformed (i.e. percent deviation from the median) values. 
We compared both total and non-seasonal monthly variation in spawning output and recruitment strength. When considering total variation we used one median, maximum and minimum value for each entire multiyear data set. When comparing wet versus dry season activity we used a single median value for all months in each season. To examine overall non-seasonal variation we removed the effects of seasonal variation by using the maximum, minimum and median values from each of the 12 mo. Whenever Levene's Test detected a significant difference between variation in spawning and recruitment we used a multiplicative Mann-Whitney U-test (see Zar 1974) to establish the minimum factor by which they differed: the amount by which each of the set of values with the smaller median had to be multiplied to obtain a $U$ value with a $p>0.05$.

Our analysis of intermensual variation in spawning and recruitment is in 2 parts. First we assume that the local population is not self-recruiting (but that the level of variation in spawning that we observed is representative of that at the recruits' origin) and ask the question: (1) 'Does the level of variation in spawning differ from that in recruitment in each species?' Then we assume that the local population is self-recruiting and ask 2 further questions: (2) 'Does the level of recruitment in a month depend on the level of spawning that produced that recruitment?' (3) 'By what factor does the level of recruitment differ from the level of spawning that produced that recruitment?'

To answer Question 2 we ran cross-correlations between seasonally-adjusted values for spawning output and recruitment (using SYSTAT 1988), with recruitment lagged by 1 mo to account for the larval duration (see above). Prior to performing those crosscorrelations any significant autocorrelations in each series were removed by first-difference transformation of the data (Cohen et al. 1986, Thompson \& Page 1989). To examine Question 3 we reduced monthly values for spawning output and recruitment to a common scale, relative to their maximum values $(=1)$. The larger of the scaled values of either spawning or 'resultant' recruitment for each month was then divided by the smaller of the two to obtain the level of the difference between them. These difference values provided a measure of the degree to which pelagic processes increased or decreased recruitment strength in relation to spawning strength.

Interannual variation in spawning and recruitment: Variation in a population's spawning output depends on both per capita output and population size. We measured per capita output. Average adult life spans of our study species are on the order of $1 \mathrm{yr}$ or more, and there are no consistent patterns of seasonal change in population size of any measured (D.R.R. unpubl. data). Thus variation in population size is unlikely to influence intermensual variation in spawning, and we restrict our attention to its potential effect on interannual variation in spawning. To estimate the potential range of interannual variation in population spawning output of each species we multiplied the range of per capita spawning values observed during the present study by the average proportionate change in population size that occurred over all $3 \mathrm{yr}$ periods for which there were data (Table 2). Those proportionate changes in population size were determined from annual censuses of populations of each species (D.R.R. unpubl. data).

When making multiple comparisons of levels of variation in spawning and recruitment of different species we used the Bonferroni technique (Rice 1989) to adjust significance levels when variances were homogeneous, and the Games and Howell method (Sokal \& Rohlf 1981) when variances were heterogeneous.

\section{RESULTS}

\section{Magnitude of intermensual variation in spawning and recruitment}

In 5 species (i.e. all except Stegastes leucostictus), spawning output varied 5- to 9-fold overall, and 3- to 7 fold when effects of seasonal variation were removed (Table 3). The range of variation in recruitment was 10 to 15 times as great as that in spawning in those 5 species (Table 3). Similarities in the range of variation in the spawning and recruitment of $S$. leucostictus reflect the absence of spawning and recruitment in some months

The level of total variation in recruitment was significantly greater than the level of total variation in spawning output in each of the 6 species (Table 3). Non-seasonal variation in recruitment exceeded that in spawning in all species when all data on recruitment

Table 2. Interannual variation in sizes of adult populations of 4 species of Caribbean damselfishes (based on unpubl. data of D. R. Robertson). Proportionate change in population = largest population value/smallest population value in each 3 -consecutive-year period. n: no. of 3 yr periods. Population size: combined size of all populations on at least 25 patch reefs per species

\begin{tabular}{|lccc|}
\hline Species & \multicolumn{2}{c}{$\begin{array}{c}\text { Proportionate change } \\
\text { in population size } \\
\end{array}$} & $\mathrm{n}$ \\
& Average & Range & \\
\hline Stegastes diencaeus & 1.37 & $1.06-1.83$ & 9 \\
Stegastes dorsopunicans & 1.21 & $1.14-1.27$ & 2 \\
Stegastes leucostictus & 1.70 & $1.09-2.17$ & 3 \\
Stegastes partitus & 1.13 & $1.09-1.17$ & 5 \\
\hline
\end{tabular}




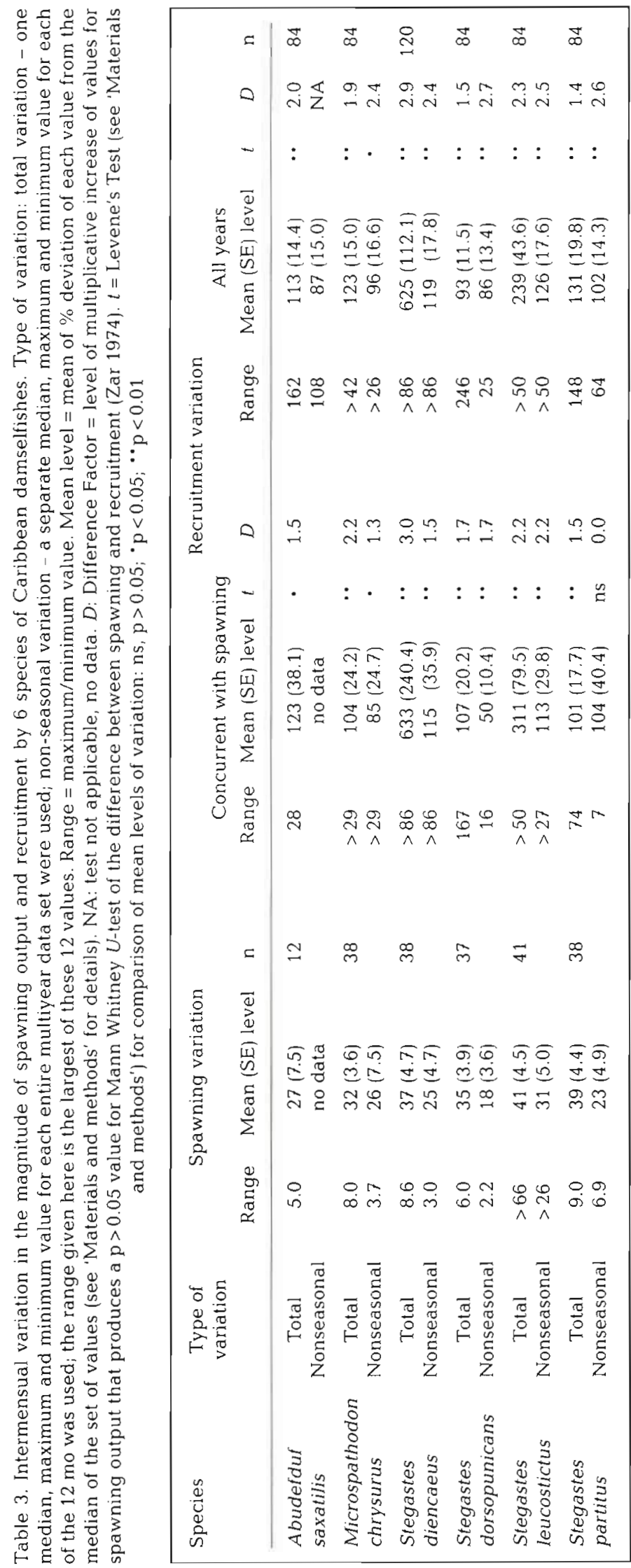

were included in the analyses. When the analyses were restricted to concurrently collected data, variation in recruitment exceeded that in spawning in all species except Stegastes partitus (Table 3). Mean levels of variation in recruitment were about 3 to 4 times greater than those in spawning output in 5 species and 5 to 20 times greater in the sixth ( $S$. diencaeus). The $U$-tests indicate that variation in recruitment exceeded variation in spawning by factors of at least 1.5 to 3.0 (Table 3). These differences between spawning and recruitment are not due to differences in sample sizes (recruitment was monitored for much longer than spawning) because levels of variation in recruitment during the $3 \mathrm{yr}$ when spawning was monitored were essentially the same as levels over the longer term (Table 3 ).

There were no significant differences between levels of variation in spawning output during the wet and dry seasons in any species (Table 4). Levels of variation in recruitment did not differ in the 2 seasons in 5 species, while limitations in the data make the situation unclear in the sixth (Stegastes diencaeus; Table 4). However, because of the relatively small sample sizes for recruitment and, especially, spawning in the dry season, and the large variances in activity, the power of this set of tests to detect even moderate differences in the means is not high (Table 4).

There were no significant differences among the 5 species in levels of variation in total or nonseasonal spawning output (multiple comparisons of means in Table 3, all $p>0.05$ ). Levels of total variation in recruitment did not differ between Stegastes diencaeus and $S$. leucostictus, or among the other 3 species $(p>0.05)$. However, total variation in the recruitment of both $S$. diencaeus and $S$. leucostictus differed (at $p<0.05$ ) from levels in the remaining 3 species. Levels of non-seasonal variation in recruitment did not differ among the species (Table 3 , multiple comparisons, all $\mathrm{p}>0.05$ ).

\section{Serial change in spawning and recruitment}

Serial mensual change in seasonally-adjusted spawning output and 'resultant' recruitment were not correlated in any species (Microspathodon chrysurus: $\mathrm{r}=0.08$; Stegastes diencaeus: $\mathrm{r}=-0.11$; $S$. dorsopunicans: $\mathrm{r}=0.10 ; S$, partitus: $\mathrm{r}=-0.12$ ). Average degrees of difference between levels of spawning and 'resultant' recruitment ranged from 3 - to 20-fold among the 6 species, while maximum degrees of difference ranged from 15- to 100-fold among those species monitored for $>1$ yr (Table 5). 
Table 4. Intermensual variation in spawning output and recruitment by 6 species of Caribbean damselfishes during the wet and dry seasons. Mean level of variation - see Table 3 and 'Materials and methods' for details. $t=$ Levene's $t$-test for difference between means: $n s, p>0.05 ; 1-\beta=$ power of test to detect that one mean is half the size of the other (see Cohen 1969)

\begin{tabular}{|c|c|c|c|c|c|c|c|c|}
\hline \multirow[t]{3}{*}{ Species } & \multicolumn{8}{|c|}{ Mean (SE) level of variation } \\
\hline & \multicolumn{4}{|c|}{ Spawning output } & \multicolumn{4}{|c|}{ Recruitment } \\
\hline & Dry season & $\mathrm{n}$ & Wet season & $n(t, 1-\beta)$ & Dry season & $\mathrm{n}$ & Wet season & $\mathrm{n}(t, 1-\beta)$ \\
\hline Abudefduf saxatilis & $70.6(34.3)$ & 4 & $24.3(9.0)$ & 8 (ns, .15) & $72.1(15.4)$ & 20 & $66.8(11.3)$ & 41 (ns, .43) \\
\hline Microspathodon chrysurus & $43.4(13.9)$ & 12 & $24.7(3.8)$ & $26(\mathrm{~ns}, 28)$ & $78.3(16.1\}$ & 20 & $109.6(15.3)$ & 44 (ns, .45) \\
\hline Stegastes diencaeus & $39.2(8.3)$ & 12 & $28.0(4.4)$ & 24 (ns, .28) & $\mathrm{NA}^{\mathrm{d}}$ & 31 & $211.7(35.1)$ & $64\left(\mathrm{NA}^{\mathrm{d}},-\right)$ \\
\hline Stegastes dorsopunicans & $33.8 \quad(6.4)$ & 12 & $34.0(4.3)$ & $25\left(\mathrm{~ns}_{1}, 29\right)$ & $120.6(43.5)$ & 20 & $87.6(15.3)$ & 45 (ns, .45) \\
\hline Stegastes leucostictus & $36.6 \quad(8.9)$ & 12 & $44.1(5.3)$ & $29(n s, .29)$ & $127.6(26.5)$ & 20 & $229.3(70.2)$ & 41 (ns, .43) \\
\hline Stegastes partitus & $45.3 \quad(9.5)$ & 12 & $32.9(3.8)$ & $26(n s, 31)$ & $33.1(42.9)$ & 22 & $95.9(17.8)$ & 43 (ns, .46) \\
\hline
\end{tabular}

\section{Interannual variation in spawning and recruitment}

Levels of variation in recruitment and spawning output differed in only 1 of 5 species (Stegastes diencaeus), in which recruitment was more variable than spawning (Table 6). This also was the only species in which the range of variation in recruitment was obviously much larger than the range of variation in spawning (Table 6). When changes in sizes of adult populations were taken into account, the estimated range of variation in spawning output differed noticeably from that in recruitment only in $S$. diencaeus (Table 6).

There were no differences among the species in levels of interannual variation in spawning output (multiple comparisons of means in Table 6). Differences among the species in levels of interannual variation in recruitment involved Stegastes diencaeus, with each of $S$. leucostictus, $S$. partitus and Abudefduf saxatilis (at $\mathrm{p}<0.05$, multiple comparisons of means in Table 6).

\section{DISCUSSION}

Fish that recruit onto reefs in the general area of San Blas Point may be produced outside that area. If so and if our assumptions (about levels of variation in spawning, relations between egg and larval production, and relations between settlement and recruitment) are correct, then differences between levels of variation in spawning and recruitment should be due to pelagic processes. What is the magnitude of the effects of pelagic processes on variability in recruitment on different time scales and do those processes act in the same way on different species?

Our data indicate that pelagic processes increase intermensual variability in recruitment over that expected due to spawning by averages of at least
1.5- to 3.0-fold and perhaps by as much as 10 - to 15-fold. Neither spawning nor recruitment appeared to be more variable in one season than the other in any species. In addition, levels of variation in spawning output and levels of non-seasonal variation in recruitment did not differ among the species. Interspecific differences in recruitment patterns were observed only in total intermensual and interannual levels of variation (present data) and in seasonal cycles of activity (Robertson 1990); the former differences reflect interspecific variation in the degree of seasonality in recruitment (Robertson 1990). These data indicate that interspecific differences in recruitment patterns of these species are produced mainly by seasonal change in the base level of activity of pelagic processes that determine larval survival, and that those processes show minimal seasonal change in the degree of variability in their activity.

Damselfish populations on the San Blas Point reef system may be self-recruiting. In that case the lack of a correlation between serial subseasonal change in spawning and 'resultant' recruitment in any species indicates that pelagic processes have overriding con-

Table 5. Degree of difference in the level of spawning output in a month and the level of recruitment that 'results' from that month's spawning in 6 species of Caribbean damselfishes. Difference value = larger of each month's scaled $(\max =1)$ spawning and recruitment values divided by the smaller of the two

\begin{tabular}{|lrcc|}
\hline \multirow{2}{*}{ Species } & \multicolumn{2}{c}{ Difference value } & $\mathrm{n}$ \\
& Average & Maximum & \\
\hline Abudefduf saxatilis & 3.3 & 7 & 12 \\
Microspathodon chrysurus & 4.7 & 26 & 38 \\
Stegastes diencaeus & 20.7 & 83 & 38 \\
Stegastes dorsopunicans & 8.0 & 72 & 37 \\
Stegastes leucostictus & 20.8 & 106 & 43 \\
Stegastes partitus & 3.8 & 15 & 44 \\
\hline
\end{tabular}


Table 6. Interannual variation in the magnitude of spawning output and recruitment by 6 species of Caribbean damselfishes. Pop.: estimated population value $=$ per capita value $\times$ average interannual proportional change in population size (from Table 2 ) . Mean $=$ mean \% deviation from the median (see 'Materials and methods' for details). Concurrent $=$ recorded during the period when spawning was monitored. ND = no data on per capita output and/or change in population size. $t=$ Levene's Test: per capita mean for spawning vs all years mean for recruitment: $n s=p>0.05,{ }^{\circ}=p<0.05$

\begin{tabular}{|c|c|c|c|c|c|c|c|c|c|c|c|}
\hline \multirow[t]{3}{*}{ Species } & \multicolumn{4}{|c|}{ Spawning variation } & \multicolumn{7}{|c|}{ Recruitment variation } \\
\hline & \multicolumn{2}{|c|}{ Range } & \multicolumn{2}{|c|}{ Per capita } & \multicolumn{3}{|c|}{ Concurrent with spawning } & \multicolumn{4}{|c|}{ All years } \\
\hline & Per capita & Pop. & Mean (SE) & $\mathrm{n}$ & Range & Mean & $\mathrm{n}$ & Range & Mean (SE) & $\mathrm{n}$ & $t$ \\
\hline Abudefduf saxatilis & ND & ND & ND & & ND & ND & & 1.8 & $13.3(4.8)$ & 7 & - \\
\hline Microspathodon chrysurus & IS 1.4 & ND & $10.2(8.6)$ & 3 & 1.9 & 19.0 & 3 & 1.9 & $26.4(8.8)$ & 7 & ns \\
\hline Stegastes diencaeus & 1.7 & 2.3 & $16.3(8.5)$ & 3 & 2.1 & 57.0 & 3 & 12.3 & $52.7(8.3)$ & 10 & $\cdot$ \\
\hline Stegastes dorsopunicans & 1.4 & 1.7 & $9.7(8.4)$ & 3 & 1.6 & 12.2 & 3 & 2.5 & $21.2(5.9)$ & 7 & ns \\
\hline Stegastes leucostictus & 1.6 & 2.2 & $12.3(11.1)$ & 3 & 1.4 & 6.8 & 3 & 1.6 & $12.3(6.9)$ & 7 & ns \\
\hline Stegastes partitus & 1.2 & 1.4 & $7.5(4.7)$ & 3 & 1.2 & 7.4 & 3 & 2.1 & $17.7(4.7)$ & 7 & $\mathrm{~ns}$ \\
\hline
\end{tabular}

trol over recruitment strength in all species. Those processes would not only determine the serial pattern of monthly variation in recruitment strength, but would also greatly increase (by 4 - to 20 -fold on average and up to 15 - to 100 -fold in the extreme) variation in it over what could be expected due to variation in spawning.

In 5 of our 6 study species interannual variation in recruitment is not only at the low end of the range of values recorded for similar reef fishes at other sites (primarily in the West Pacific; Doherty \& Williams 1988 , but is about the same as or only slightly greater than interannual variation in spawning. Thus although short-term pelagic processes controlled and substantially increased intermensual variation in recruitment this evidently had little or no net effect on year-class recruitment strength in most species.

The exception among this group of species is Stegastes diencaeus, which has distinctly higher interannual variation in recruitment than the others. It also differs from them in the strength (but not the timing) of its recruitment seasonality (Robertson 1990). Even in years when recruits of $S$. diencaeus were most abundant they still were rare relative to those of all other Stegastes spp. (D.R.R. unpubl, data). From this it appears that pelagic processes that control the recruitment of $S$. diencaeus are somewhat species specific in their action, are usually unfavorable to survival of its larvae, and tend to be unfavorable throughout entire years.

The data on short- and long-term variation in the intensity of spawning and recruitment presented here and elsewhere (Robertson 1990) on the seasonality of reproduction indicate that the widely held view that recruitment strength in temperate marine fishes is controlled primarily by pelagic processes affecting larval survival and promoting variation in recruitment should be applied to tropical reef fishes. Dependency of recruitment strength on spawning output is unlikely in highly fecund fishes (which damselfishes are, e.g. Doherty 1983) that necessarily have high larval mortality, because small changes in larval mortality rates can lead to large changes in recruitment strength (Koslow 1992, see also Shulman \& Ogden 1987).

No data have yet been published on the larval biology of tropical reef fishes that bear directly on the question of what pelagic processes determine larval survivorship and affect recruitment levels. Very little is known about larval growth and mortality in such species (Thorrold \& Milicich 1990), and the origin of pelagic juveniles that recruit onto a particular reef within a large reef system (e.g. the Caribbean) is not known for any case. Pelagic processes that control monthly recruitment strength of San Blas damselfishes could act at any point between the release of hatchlings just after dusk and the settlement of juveniles onto a reef at night about a month later. Pelagic larvae of West-Pacific damselfishes typically are found close to reefs and larvae of different taxa of these fishes, including some congeneric taxa, can have different (and dielly and ontogenetically changing) horizontal and vertical distributions in near-reef waters (Leis 1986, 1991a, b). Such differences, or others associated with other aspects of the ecology of larvae, could be involved in producing consistent patterns of interspecific variation in recruitment. Research is lacking on these aspects of the ecology of fish larvae in the Caribbean and knowledge of the oceanography of the Caribbean waters of Panama is limited to a general idea of large-scale water currents (see Lessios et al. 1984 for summary) and to characterisation of the coastal weather regime (Cubit et al. 1989).

Some reef fishes (including damselfishes) at intermediate and higher tropical latitudes show moderately strong seasonality in their reproduction and recruitment. At more equatorial locations other species, such as those discussed here, exhibit seasonally more extended or year-round spawning and recruitment. 
Relationships between reproductive seasonality and environmental seasonality vary among those sites (Robertson 1991). Interannual variation in recruitment of most of the present study species appears to be low in comparison to levels recorded for damselfishes elsewhere (e.g. Doherty \& Williams 1988). Such differences in levels of variation could arise in 2 ways. First, pelagic processes that control settlement success of many species simply may have relatively low variability in the comparatively more benign environment of the South-West Caribbean. Second, if recruitment is effectively possible during only a short period each year then short-term adversity in environmental conditions that control larval survival could lead to failure of an entire year class of recruits and so to high interannual recruitment variation. When recruitment can occur throughout all or most or the year similar shortterm evironmental change would have less effect on a year's recruitment level and hence on interannual recruitment variation. Comprehensive analyses of relations between recruitment seasonality and variation in recruitment strength within and among various taxa of fishes at those and other sites could be useful in revealing how pelagic processes produce geographic differences in the temporal structure of recruitment that would impact on the dynamics of benthic populations and communities.

Acknowledgements. This research was supported by Smithsonian Institution's Scholarly Studies Program, general research funds from STRI, and a post-doctoral research grant from Virginia Polytechnic Institute and State University to J.D.B. Many of the data on spawning were collected by $\mathrm{K}$. Andersen, J. Arnold, L. Fore, J Hampel, J. Jolly, A Lent, P. Mace, K. Niessen, D. Pilson, R. Riley, D. Wachter and C. White. A. Cedeño assisted during the collection of data on recruitment. We thank the Kuna General Congress and the Government of the Republic of Panama for permitting field work in the San Blas area. J. Christy, H. Lessios, G. Wellington and 2 reviewers made useful comments on drafts of the paper.

\section{LITERATURE CITED}

Bakun, A. J., Beyer, J., Pauly, D., Pope, J. G., Sharp, G. D. (1982). Ocean sciences in relation to living resources. Can. J. Fish. Aquat Sci. 39: 1059-1070

Booth, D. J. (1991). The effects of sampling frequency on estimates of recruitment of the domino damselfish Dascyllus albisella Gill. J. exp. mar. Biol. Ecol. 145: $149-159$

Checkley, D. M. Jr, Raman, S., Maillet, G. L., Mason, M. (1988). Winter storm effects on the spawning and larval drift of a pelagic fish. Nature 335: 346-348

Cohen, E. B., Mountain, D. G., O'Boyle, R. N. (1986). Absence of large scale coherence in cod and haddock recruitment in the Northwest Atlantic. Comm. Meet. Int. Coun. Explor. Sea C.M.-[CES/G:89
Cohen, J. (1969). Statistical power analysis for the behavioral sciences. Academic Press, New York

Cubit, J. D., Caffey, H. M., Thompson, R. C. (1989). The physical environment of a shoaling reef flat on the Caribbean coast of Panama: range of variation, seasonal patterns, and biological significance. Coral Reefs 8: 59-66

Cushing, D. H. (1975). Marine ecology and fisheries. Cambridge University Press, Cambridge

Cushing, D. H. (1982). Climate and fisheries. Academic Press, New York

Doherty, P. J. (1980). Biological and physical constraints on the population of two sympatric territorial damselfishes of the Southern Great Barrier Reef. Ph.D. thesis, University of Sydney

Doherty, P. J. (1983). Diel, lunar and seasonal rhythms in the reproduction of two tropical damselfishes: Pomacentrus flavicauda and P. wardi. Mar. Biol. 75: 215-224

Doherty, P. J. (1991). Spatial and temporal patterns in recruitment. In: Sale, P. F. (ed.) The ecology of fishes on coral reefs. Academic Press, San Diego, p. 261-293

Doherty, P. J., Sale, P. F. (1986). Predation on juvenile coral reef fishes: an exclusion experiment. Coral Reefs 5: $161-163$

Doherty, P. J., Williams, D. McB. (1988). The replenishment of coral reef fish populations. Oceanogr. mar. Biol. A. Rev. 26: $487-551$

Forrester, G. (1990). Factors influencing the juvenile demography of a coral reef fish. Ecology 71: 1666-1681

Hennemuth, R. C., Palmer, J. E., Brown, B. E. (1980). A statistical description of recruitment in eighteen fish stocks. J. Northw. Atl. Fish Sci. 1: 101-111

Koslow, J. A. (1992). Fecundity and the stock-recruitment relationship. Can. J. Fish. Aquat. Sci. 49: 210-217

Koslow, J. A., Thompson, K. R. (1987). Recruitment of northwest Atlantic cod (Gadus morhua) and haddock (Melanogrammus aeglefinus) stocks: influence of stock size and climate. Can. J. Fish. Aquat. Sci. 44: 26-39

Lambert, T. C., Ware, D. M. (1984). Reproductive strategies of demersal and pelagic spawning fish. Can. J. Fish. Aquat. Sci. 41: 1565-1569

Lasker, R. (1981). The role of a stable ocean in larval fish survival and subsequent recruitment. In: Lasker, R. (ed.) Marine fish larvae: morphology, ecology and relation to fisheries. Washington Sea Grant Program, University of Washington, Seattle, p. 80-87

Leis, J. M. (1986). Vertical and horizontal distributions of fish larvae near coral reefs at Lizard Island, Great Barrier Reef. Mar. Biol. 90: 505-516

Leis, J. M. (1991a). The pelagic stage of reef fishes: the larval biology of coral reef fishes. In: Sale, P. F. (ed.) Ecology of fishes on coral reefs. Academic Press, San Diego, p. $183-230$

Leis, J. M. (1991b). Vertical distributions of fish larvae in the Great Barrier Reef lagoon, Australia. Mar. Biol. 109: $157-166$

Lessios, H. A., Robertson, D. R., Cubit, J. D. (1984). Spread of Diadema mass mortality through the Caribbean. Science 226: 335-337

MacFarland, W. N., Brothers, E. B., Ogden, J. C., Shulman, M. J., Bermingham, E. L., Kotchian-Prentiss, N. M. (1985). Recruitment patterns in young french grunts, Haemulon flavolineatum (family Haemulidae) at St. Croix, U.S.V.I. Fish. Bull. U.S. 83: 413-426

Milicich, M. J., Meekan, M. G., Doherty, P. J. (1992). Larval supply: a good predictor of recruitment of three species of reef fish (Pomacentridae). Mar. Ecol. Prog. Ser. 86: $153-166$ 
Parrish, R. H., Nelson, C. S., Bakun, A. (1981). Transport mechanisms and reproductive success of fishes in the California current. Biol. Oceanogr. 1 175-203

Peterman, R., Bradford, M. J. (1987). Wind speed and mortality rate of a marine fish, the northern anchovy (Engraulis mordax). Science 235: 354-356

Rice, W. R. (1989). Analyzing tables of statistical tests. Evolution 43: $223-225$

Robertson, D. R. (1987). Responses of two coral reef toadfishes (Batrachoididae) to the demise of their primary prey, the seaurchin Diadema antillarum. Copeia 1987: 637-642

Robertson, D. R. (1990). Differences in the seasonalities of spawning and recruitment of some small neotropical reef fishes. J. exp. mar. Biol. Ecol. 144: 49-62

Robertson, D. R. (1991). The role of adult biology in the timing of spawning of tropical reef fishes. In: Sale, P. F. (ed.) The ecology of fishes on coral reefs. Academic Press, San Diego, p. 356-386

Robertson, D. R. (1992). Patterns of lunar settlement and early recruitment in Caribbean reef fishes at Panama. Mar. Biol. $114: 527-537$

Robertson, D. R., Green, D. G., Victor, B. (1988). Temporal coupling of the production and recruitment of larvae of $a$ Caribbean reef fish. Ecology 69: 370-381

Robertson, D. R., Petersen, C. W., Brawn, J. D. (1990). Lunar reproductive cycles of benthic-brooding reef fishes: reflections of larval biology or adult biology? Ecol. Monogr. 60: 311-329

Rothschild, B. J. (1986). Dynamics of marine fish populations. Harvard University, Cambridge

Russell, B. C., Andersen, G. R. V., Talbot, F. H. (1977). Seasonality and recruitment of coral reef fishes. Aust. J. mar. Freshwat. Res. 28: 521-528

Sale, P. F., Doherty, P. J., Eckert, G. J., Douglas, W. A., Ferrel, D. J. (1984). Large scale spatial and temporal variation in recruitment of fish populations in coral reefs. Oecologia 64: $191-198$

Sale, P. F., Ferrel, D. J. (1988). Early survivorship of juvenile coral reef fishes. Coral Reefs 7: 117-124

This article was presented by J. M. Lawrence, Tampa, Florida, USA
Schultz, B. B. (1985). Levene's Test for relative variation. Syst. Zool. 34: 449-456

Sherman, K., Smith, W., Morse, W., Benua, M., Green, J. Ejsymont, J. (1984). Spawning strategies of fishes in relation to circulation, phytoplankton products, and pulses in zooplankton off the North-eastern United States. Mar. Ecol. Prog. Ser. 18: 1-19

Shulman, M. J., Ogden, J. C. (1987). What controls tropical reef fish populations: recruitment or benthic mortality? An example in the Caribbean reef fish Haemulon flavolineatum. Mar. Ecol. Prog. Ser. 39: 233-242

Sokal, R. R., Rohlf, F. J (1981). Biometry, 2nd edn. W. H Freeman and Co., New York

SYSTAT (1988). The system for statistics. Systat, Evanston, IL

Thompson, K. R., Page, F. H. (1989). Detecting synchrony of recruitment using short, autocorrelated time series. Can. J. Fish. Aquat. Sci. 46: 1831-1838

Thorrold, S. R., Milicich, M. J. (1990). Comparison of larval duration and pre- and post-settlement growth in two species of damselfish. Chromis atripectoralis and Pomacentrus coelestis (Pisces:Pomacentridae), from the Great Barrier Reef. Mar. Biol. 105: 375-384

Thresher, R. E., Harris, G. P., Gunn, J. S., Clementson, L. A. (1989). Phytoplankton production pulses and episodic settlement of a temperate marine fish. Nature 341: 641-643

Thresher, R. E., Brothers, E. B. (1989). Evidenced intraand inter-oceanic regional differences in the early life history of reef associated fishes. Mar Ecol. Prog. Ser. 57 : $187-205$

Victor, B. C. (1986). Larval settlement and juvenile mortality in a recruitment-limited coral reef fish population. Ecol. Monogr. 56: 145-160

Wellington, G. M., Victor, B. C. (1989). Planktonic larvae duration of one hundred species of Pacific and Atlantic damselfishes (Pomacentridae). Mar. Biol. 101: $555-567$

Zar, J. H. (1974). Biostatistical analysis. Prentice-Hall, Englewood Cliffs

Manuscript first received: July 6, 1992

Revised version accepted: January 25, 1993 